\title{
Mirándonos al espejo: narrativas sobre el proceso colonial en la isla de Mallorca durante la Edad del Hierro (850-123 aC)
}

\author{
Our reflection in the mirror: narratives of the colonial \\ process in Mallorca during the Iron Age (850-123 BC)
}

\section{Manuel Calvo Trías}

Universitat de les Illes Balears. Grupo de investigación ArqueoUIB Ctra. Valldemossa, km 7,5. Edifici Ramon Llull, E-07122 Palma Manuel.calvo@uib.es

\section{JAUMe GARcía Rosselló}

Universitat de les Illes Balears. Grupo de investigación ArqueoUIB Ctra. Valldemossa, km 7,5. Edifici Ramon Llull, E-07122 Palma Jaume.garcia@uib.es

El trabajo que presentamos tiene por objetivo analizar las diferentes estrategias de investigación que se han implementado en la isla de Mallorca a la hora de estudiar e interpretar el significado y el alcance que tuvieron los contactos que se desarrollaron a lo largo de la segunda Edad del Hierro entre las comunidades indígenas y las foráneas, especialmente las procedentes de Ibiza. El estudio se desarrollará a partir de tres ejes básicos: un breve análisis de las praxis arqueológicas y de los principales agentes de la época, un análisis de las bases teórico-metodológicas sobre las que se basan y, finalmente, un análisis de las principales narrativas. Ello supone aceptar la premisa de que no existe una única manera válida de historiar un determinado fenómeno, sino que existen múltiples y variadas propuestas que parten de premisas teóricas distintas, de contextos científicos y sociales diferentes $y$, sobre todo, persiguen finalidades y desempeñan funciones muy diversas. 
This article considers the diverse research strategies applied in Mallorca island for the analysis and interpretation of the significance and reach of the contacts between indigenous and foreign communities during the Iron Age II, particularly in the case of Ibiza populations. This study follows three basic guidelines: a brief analysis of archaeological praxis and the main agents operating at the time, the revision of the theoretical-methodological basis they rested on and, finally, an overview of the main narratives. Hence it implies accepting the premise that there is not an only valid approach to narrate a certain phenomenon, but rather multiple and varied proposals may coexist, any of them developed from different theoretical premises, scientific and social contexts and, above all, following highly different aims and functions.

\section{KEYWORDS}

PUNIC, POST-TALAYOTIC, COLONIALISM, MALLORCA ISLAND, POSTCOLONIALISM

A la memoria de Víctor Guerrero

Essentially, all models are wrong, but some are useful

Box, 1979

\section{Introducción}

La Edad del Hierro supone el inicio, y posterior desarrollo, de la presencia fenicio-púnica en el archipiélago balear. Dicha situación adquiere ciertas características propias que la hacen singular, puesto que la ocupación fenicio-púnica se centró, en un primer momento, únicamente en Ibiza y más tarde también en Formentera. Sin embargo, para las islas mayores de Mallorca y Menorca, más allá del establecimiento en algún islote, no puede hablarse de una ocupación territorial colonial antes de la conquista romana en el año 123 aC. Esta situación diferencial hizo que el devenir histórico de las islas Baleares se dividiese. De este modo, las Pitiusas (Ibiza y Formentera) serían plenamente fenicias primero y púnicas después, mientras que en las islas de Mallorca y Menorca se mantuvo el protagonismo de las comunidades indígenas que establecieron una compleja red de relaciones con el mundo fenicio-púnico (fig. 1).

Este diferente devenir histórico ha marcado las estrategias de investigación desarrolladas en cada una de las islas. Las Pitiusas quedan insertas en la fuerte tradición de la arqueología protohistórica y su desarrollo colonial. En estas islas, el peso de la tradición científica y de la materialidad arqueológica fenicio-púnica es tan marcado que las investigaciones de épocas prefenicias han quedado, en muchos momentos, en un segundo lugar. Por el contrario, en Mallorca y Menorca las praxis arqueológicas se han desarrollado en otra dirección, con un peso fundamental del estudio y análisis de la cultura talayótica y postalayótica que, en ocasiones, también ha marginado la investigación de otras fases y períodos de su prehistoria.

Sin embargo, en la isla de Mallorca hay un momento en que ambas tradiciones se entrecruzan, puesto que la segunda Edad del Hierro supone no solo la presencia de abun- 


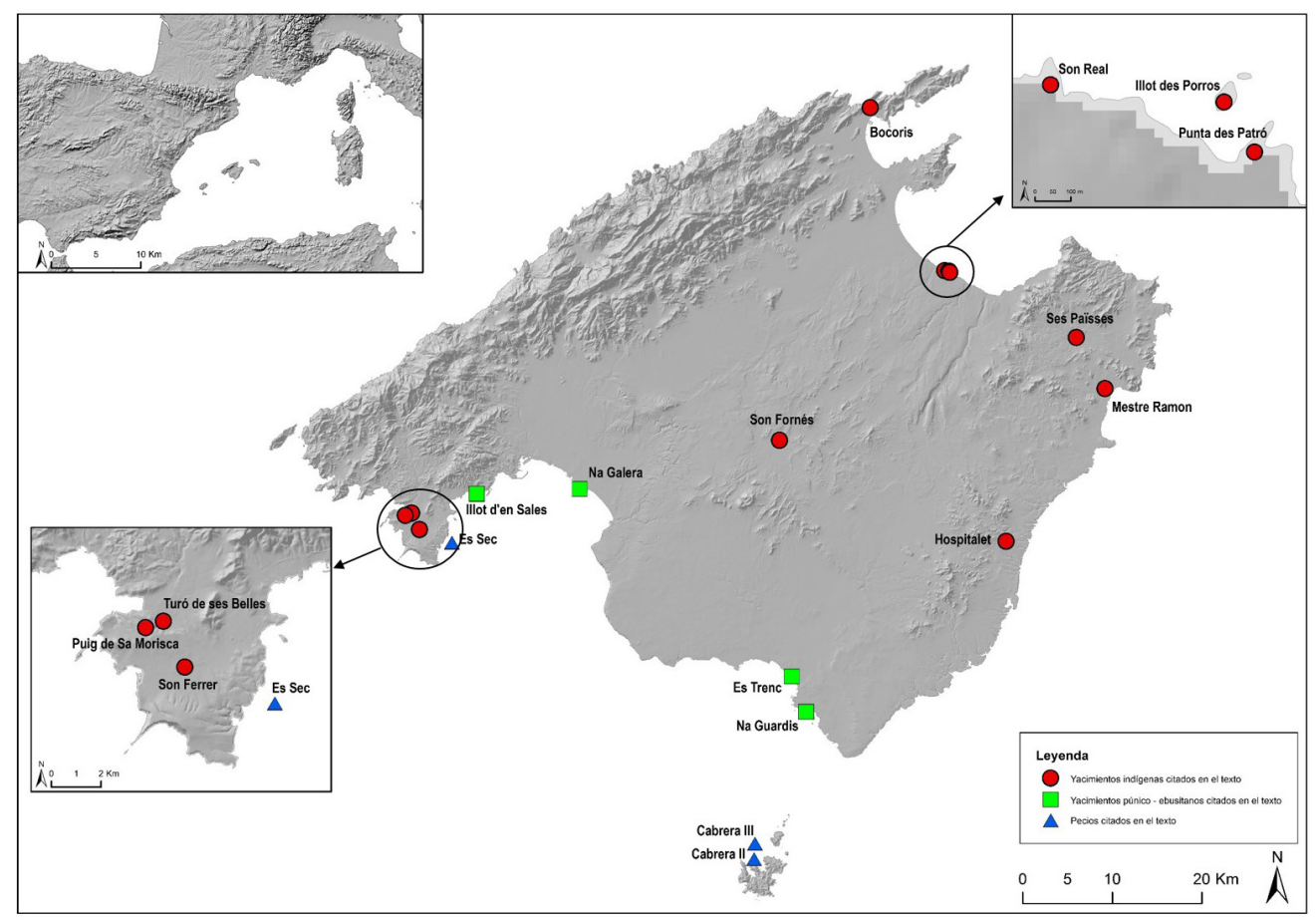

Figura 1. Mapa con la localización de los principales yacimientos citados en el texto.

dantes materiales ebusitanos en yacimientos postalayóticos (Hernández y Quintana, 2013; Ramón, 2017) sino también, la ocupación ebusitana, más o menos temporal, de islotes cercanos a las costas de Mallorca como Na Guardis, Na Galera o S'Illot d'en Sales (Guerrero, 1981, 1997; Martín et al., 2015) (fig. 1).

Con este trabajo pretendemos realizar un análisis historiográfico de los distintos marcos conceptuales y teóricos sobre los que se han construido las diferentes narrativas interpretativas de la relación entre las comunidades púnicas y las comunidades indígenas de Mallorca durante la Edad del Hierro.

\section{Planteamientos y perspectivas de análisis}

Son múltiples las estrategias que se pueden seguir a la hora de abordar el estudio de las praxis arqueológicas y científicas de un determinado fenómeno. Las diferencias en el enfoque y en los referentes usados dependen de multitud de factores que van desde el planteamiento teórico del que se parte, hasta el contexto y la praxis donde se inscribe el autor, pasando 
por multitud de aspectos en los que cobra un papel esencial el objetivo y la finalidad que inspira la investigación (Díaz-Andreu, 2002). Por ello, nuestro planteamiento a la hora de analizar y valorar las diferentes estrategias seguidas por los investigadores a lo largo de los últimos setenta y cinco años se aleja de propuestas normativistas orientadas a establecer la validez de las interpretaciones de cada momento. Por el contrario, entendemos que cada propuesta adquiere sentido dentro del contexto histórico en el que se desarrolló. De esta manera, nuestro objetivo se centrará en analizar cómo se articulan, de manera inseparable, en la construcción de las diferentes narrativas, los marcos conceptuales de referencia, los datos arqueológicos disponibles, así como la praxis científica imperante en cada momento y en el contexto donde esta se desarrolla (Javaloyas, 2010).

Esto supone aceptar la premisa de que no existe una única manera válida de historiar un determinado fenómeno, sino que existen múltiples y variadas propuestas que parten de premisas teóricas distintas, de contextos científicos y sociales diferentes y, sobre todo, persiguen finalidades y desempeñan funciones muy diversas (Javaloyas, e.p.).

Sin lugar a dudas, estos discursos no surgen de la nada, sino que van directamente ligados a los postulados teórico-interpretativos de base y a todo el contexto socio-cultural donde se desarrolla la práctica arqueológica. A su vez, no es menos cierto que dichos discursos tampoco pueden desligarse de las prácticas concretas que se han desarrollado a la hora de analizar e investigar este fenómeno. Por el enfoque y la extensión del trabajo presentado incidiremos fundamentalmente en el análisis de las narrativas propuestas. Sin embargo, aunque sea tangencialmente, a lo largo del trabajo intentaremos vincular el análisis del discurso con otros elementos esenciales, como agentes, estructuras y prácticas, con el fin de entender el desarrollo de las interpretaciones propuestas dentro de un contexto más complejo y global (Sorensen, 1984; Jensen, 1997; Moro, 2007; Díaz-Andreu, 2002, Javaloyas, 2010).

El estudio se desarrollará a partir de tres ejes básicos: un breve análisis de las praxis arqueológicas y de los principales agentes de la época, un estudio de las bases teóricometodológicas en las que se basan y, finalmente, un análisis de las principales narrativas.

Con el fin de articular de una manera estructurada el trabajo propuesto, hemos dividido el estudio a partir de tres grandes etapas. Cada uno de estos momentos se corresponde con el predominio de un paradigma y una narrativa más o menos común y coherente en relación al estudio de los contactos entre las comunidades fenicio-púnicas, principalmente ebusitanas, y las comunidades postalayóticas que habitaron la isla de Mallorca durante la segunda Edad del Hierro:

- Primera etapa: Autoctonismo. De las primeras referencias a materiales púnicos a la propuesta de un modelo colonial (s. XIX- 1979)

- Segunda etapa: Construcción de un modelo colonial (1979-2009)

1. Primer momento (1979-1992)

2. Segundo momento (1992-2009)

- Tercera etapa: Nuevas reflexiones, revisiones y búsqueda de modelos (2011-2018). 


\section{Autoctonismo. De las primeras referencias a materiales púnicos a la propuesta de un modelo colonial (siglo XIX-1979)}

Esta primera fase presenta una larga extensión cronológica y agrupa un amplio número de autores y de trabajos. Se trata de un período de construcción de las primeras propuestas interpretativas de la prehistoria de Mallorca. Ello corre paralelo a un aumento significativo de los hallazgos fruto de las primeras excavaciones científicas que se iban realizando.

La práctica arqueológica de esta etapa viene marcada por dos momentos. El primero, desde 1920 hasta 1960, en el que el liderazgo y gran parte de las intervenciones vienen auspiciadas desde Cataluña, primero bajo la figura de Josep Colominas y el Institut d'Estudis Catalans y, luego, a través del catedrático de Prehistoria de la Universidad de Barcelona, Dr. Pericot, en el marco de la financiación que representó la concesión de una beca dentro del programa de la Fundación March. ${ }^{1}$ En un segundo momento, la iniciativa estará liderada por el Museo de Mallorca fundado en 1961, a través de la figura de su director, el Dr. Guillermo Rosselló Bordoy. ${ }^{2}$ Este liderazgo será compartido con investigadores de fuera de la isla como Giovanni Lilliu, de la Universidad de Sassari; Otto Frey, de la Universidad de Marburgo; el arqueólogo estadounidense William Walldren; Manuel Fernández Miranda, procedente de la Universidad Complutense de Madrid, o Miquel Tarradell, de la Universidad de Barcelona. Toda esta actividad marcará el inicio de las grandes excavaciones en los poblados talayóticos y necrópolis de la Edad del Hierro. ${ }^{3}$

Al final de esta etapa, el aumento de la actividad excavadora y el renovado interés científico por la prehistoria insular permitirá reconocer numerosos hallazgos arqueológicos de procedencia colonial y foránea en esos yacimientos.

Las primeras evidencias de los contactos entre las comunidades fenicio-púnicas y las indígenas se difunden entre la comunidad científica a partir del impacto que tendrán los descubrimientos procedentes de tres yacimientos. Nos estamos refiriendo al estudio de los materiales de los pecios del Sec y Cabrera II (Cerdà, 1978; Arribas et al., 1987) y a las primeras publicaciones del asentamiento del Turó de ses Abelles (Camps y Vallespir, 1974) que estaba siendo excavado en ese momento.

Destacan especialmente cuatro obras publicadas en la década de los años setenta y principios de los ochenta, que tendrán una clara influencia entre los investigadores, fruto de la sistematización que proponen en relación con la prehistoria de Mallorca. Estas obras se convirtieron en los referentes sobre los que se sustentó la mayor parte de las interpretaciones de este período. Nos estamos refiriendo a la obra de Lluís Pericot The Balearic Islands

1. Auspiciada por la familia de origen mallorquín March que era la propietaria de la Banca March.

2. Junto a esta labor de liderazgo del Museo de Mallorca, no podemos dejar de citar a otros investigadores que trabajaron de manera independiente vinculados a la Comisaría de Excavaciones Arqueológicas y al Servicio Nacional de Excavaciones (Javaloyas, 2010)

3. Para una visión amplia de las características de estos yacimientos, véase Plantalamor (1991) y Guerrero et al. (2002, 2006). 
in Prehistoric Times (1972); las tesis doctorales de Guillem Rosselló Bordoy, publicada con el título de La Cultura Talayótica (1973); de Manuel Fernández Miranda, titulada Secuencia Cultural de la Prehistoria de Mallorca (1978), y de William Walldren, con el nombre Balearic Prehistoric Ecology and Culture (1982). Estas obras vienen a recoger, de manera general, las grandes narrativas que caracterizan este período.

La intensa actividad de excavación, fundamentalmente en yacimientos indígenas de la segunda Edad del Hierro a lo largo de los años sesenta y setenta tuvo, entre otros aspectos, dos consecuencias clave para el tema que estamos abordando. En primer lugar, el análisis del fenómeno del contacto entre fenicios, y posteriormente púnicos, con comunidades indígenas postalayóticas ${ }^{4}$ se interpretó a partir del estudio de los hallazgos documentados en los yacimientos indígenas. En segundo lugar, la presencia de estos materiales, si bien aún no eran muy conocidos y no estaban ni mucho menos sistematizados, fueron utilizados a modo de fósiles directores como uno de los indicadores que permitieron diferenciar las últimas fases cronoculturales de la prehistoria de Mallorca.

Los análisis epistemológicos de las obras referenciales de ese momento reflejan una enorme homogeneidad en cuanto a sus planteamientos teórico-metodológicos. Estos se derivan de los postulados del historicismo cultural, a excepción de William Walldren, que, dentro de la órbita anglosajona, incorpora tempranamente algunos aspectos propios del procesualismo.

Estas obras se caracterizan por el uso de los siguientes conceptos y estrategias:

1. La identificación de la cultura material con una cultura arqueológica, y de ahí con un determinado pueblo o etnia, siguiendo los preceptos seminales de autores como Childe (1988, original 1925).

2. Un desarrollo metodológico basado en estrategias tipológicas con un peso específico de la tipología arquitectónica, donde el concepto de fósil director se ubica en un lugar central. A partir de ahí, el desarrollo de extensas comparativas tipológicas para definir lugares de procedencia y contactos, puesto que el difusionismo se convierte en la herramienta interpretativa que explica el cambio cultural. Sin embargo, para el caso que nos ocupa, la ausencia de estudios tipológicos sistemáticos del material púnico dificultó enormemente esta estrategia de trabajo. ${ }^{5}$

3. La utilización del difusionismo en su doble variante, movimiento de personas y procesos de aculturación como motor del cambio cultural.

No obstante, a la hora de caracterizar y conceptualizar el contacto entre las comunidades fenicio-púnicas y las indígenas, estos autores no incorporan una reflexión inter-

4. Para un análisis sintético de la cultura postalayótica (650/550-123 aC), consúltese Calvo y Guerrero (2011).

5. Debemos tener en cuenta que las primeras propuestas de sistematización de las producciones anfóricas ebusitanas se remontan a principios de los años ochenta (Ramón, 1981, 1991 y 1995) a partir del estudio de los alfares de la ciudad de Ebusus; con anterioridad, se contaba con la obra de Maña (1950), que, aunque permitía una primera aproximación, distaba de ser un análisis sistemático completo. 
pretativa, más allá de utilizar el término aculturación, sobre los mecanismos que definen este fenómeno. Únicamente se incide en que los motores que potenciaron el contacto, y por tanto la aculturación de las comunidades indígenas, fueron el comercio y el retorno de los mercenarios indígenas.

Esta aculturación se concretaría en tres grandes aspectos:

a) Un aumento de los materiales de importación, principalmente púnico-ebusitanos, durante las últimas fases de ocupación de los yacimientos talayóticos.

b) Un fenómeno de reproducción y readaptación de formas cerámicas púnicas que los investigadores definen como importaciones. En muchos yacimientos indígenas se documentaron formas cerámicas hechas a mano, de factura local, que se inspiraron en referentes mediterráneos diversos, destacando especialmente los materiales ebusitanos.

c) Un proceso de sincretismo religioso en el que se observa la integración e incorporación de tradiciones o rasgos que se vinculan con un origen semita. En este sentido, podríamos comentar la relación que se establece entre algunas de las tumbas de la necrópolis de Son Real (Santa Margalida, Mallorca) con el sarcófago de Khaldé (Fernández Miranda, 1978: 249), o la relación de las estatuillas de bronce encontradas en yacimientos indígenas de Mallorca con el dios semítico Reshef (Fernández Miranda, 1978: 229; Rosselló Bordoy, 1973: 195).

En cualquier caso, no se analiza en profundidad el modo e intensidad del contacto, aunque se insiste en la idea de un intercambio exclusivamente de tipo comercial. Sin embargo, acerca de este último aspecto, los autores del momento no plantean el papel que ejercieron las comunidades indígenas en relación con Ebusus y el comercio ebusitano que se desarrolla en el Mediterráneo occidental. En este sentido, son paradigmáticas las dudas que presenta Fernández Miranda a la hora de plantear si Mallorca era el lugar de destino del comercio púnico, solo una escala para la navegación o el soporte del comercio ebusitano en el Mediterráneo (Fernández Miranda, 1978: 363).

Más allá de las propuestas que presentan estos autores, y en consonancia con el paradigma teórico de la época, hay dos elementos que cabría resaltar: por una parte, la existencia de un planteamiento marcadamente actualista, con una concepción capitalista del comercio y de sus implicaciones. Por otra, la conceptualización de las comunidades indígenas como agentes pasivos, sin ninguna capacidad de agencia, ni en el modelo comercial que se plantea ni en el proceso de asimilación religiosa e identitaria observado, ni siquiera en las innovaciones tecnológicas que se aprecian, como puede observarse en la cita siguiente:

... no parece que más allá de la presencia de estos materiales, estas constituyan un elemento innovador para sus formas de vida, ni siquiera en aspectos puramente técnicos (incorporación del torno, decoraciones, etc.), pues mantienen sus antiguas técnicas e incluso llegan a imitarlas a mano toscamente de la misma forma que también con burda técnica decoran con pintura roja y sencillos motivos algunas piezas contadas. (Fernández Miranda, 1978: 363). 
Sin embargo, y de manera paradigmática, recordemos que estos autores utilizaron, como uno de los principales indicadores para la fasificación de la segunda Edad del Hierro en Mallorca, la presencia de materiales púnicos en asentamientos indígenas (Fernández Miranda, 1978; Rosselló Bordoy, 1973).

\section{La construcción de un modelo colonial (1979-2009)}

Este período va a configurar una parte esencial de las narrativas que se han dado en el estudio de los contactos entre las comunidades púnicas e indígenas en Mallorca. Desde 1979 se va a ir construyendo un modelo con unas bases teóricas que determinarán una especial visión del contacto. Dicha visión condicionará las propuestas interpretativas de las últimas décadas, así como la revisión del modelo que se está proponiendo recientemente. Estas propuestas, más allá de matizaciones y argumentaciones arqueológicas, se caracterizarán esencialmente por un modelo que propone una relación asimétrica y desigual entre las comunidades ebusitanas y las comunidades prehistóricas bajo la forma de un modelo de contacto de tipo colonial. A pesar de que todo el período que va desde 1979 hasta 2009 se caracteriza por este eje argumental, lo cierto es que esta época no puede analizarse de una manera conjunta, sino que al menos debe dividirse en dos etapas:

1. La generación del modelo colonial (1979-1992), que concibe las comunidades indígenas como meros agentes pasivos, sin capacidad de agencia.

2. La reformulación del modelo colonial existente (1992-2009), donde se otorga un mayor protagonismo a las comunidades autóctonas, aunque se mantiene el modelo de relación asimétrica propio de los enfoques colonialistas de la época.

Todas las prácticas y propuestas interpretativas del momento no pueden desligarse, ni conceptual ni cronológicamente, del impacto científico que supuso, a lo largo de la década de los ochenta, la revisión de las dinámicas de las colonias fenicio-púnicas del levante peninsular (Garnsey y Whittaker, 1978; Del Olmo y Aubet, 1986; Moscati, 1983), revisión que, en cierta manera, quedó sintetizada con la obra de M.E. Aubet Tiro y las colonias fenicias de Occidente (1987).

\subsection{El desarrollo del modelo colonial (1979-1992)}

El desarrollo de un modelo colonial para la isla de Mallorca parte del descubrimiento y posterior excavación del islote de Na Guardis (fig. 2), un islote donde se documentó por primera vez un asentamiento púnico-ebusitano en Mallorca (Guerrero, 1981, 1984). Los resultados de esta excavación fueron fundamentales para establecer los principales argu- 


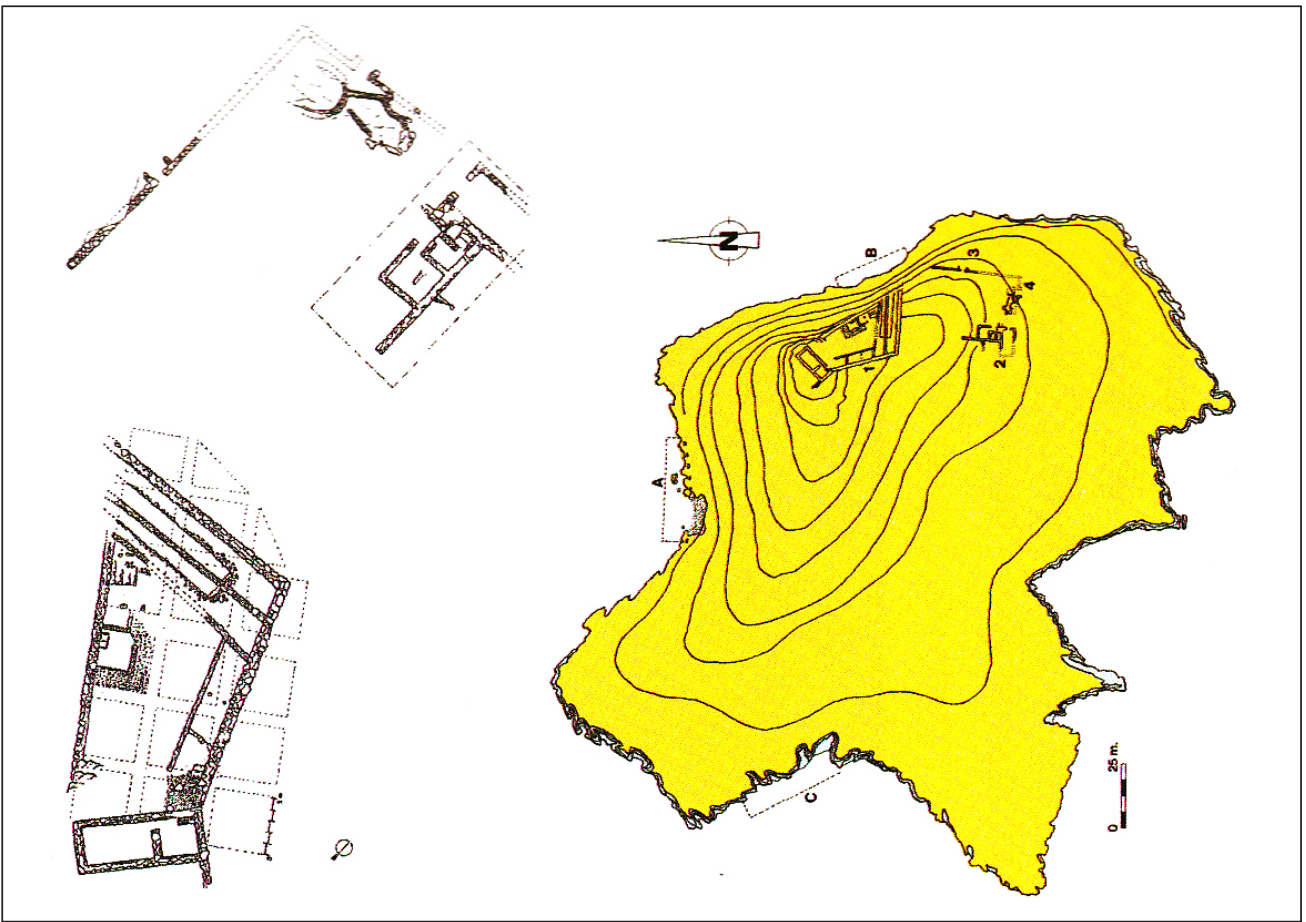

Figura 2. Factoría púnica de Na Guardis y planimetría de las zonas excavadas por Víctor Guerrero.

mentos que definieron el modelo colonial que se proponía para este período. La edición de los primeros resultados de la excavación coincidirá en el tiempo con la publicación de los primeros trabajos que defendían un modelo colonial asimétrico.

En 1984 se dan a conocer dos trabajos seminales, de Mayoral y de Guerrero. Mientras que el de Mayoral no tiene apenas continuación, Guerrero se va a convertir en el máximo exponente y defensor de dicho modelo. Es en la obra titulada Asentamiento púnico de Na Guardis (Guerrero, 1984: 212) donde se habla por primera vez de "un proceso colonizador».

El inicio de la construcción de este modelo interpretativo coincide también con algunos cambios en las praxis científicas. Hasta el momento había un predominio de excavaciones en grandes poblados talayóticos y necrópolis. Frente a esta situación, desde el principio de la década de los años ochenta hay una disminución de este tipo de excavaciones, cobrando un mayor protagonismo las intervenciones de yacimientos estrictamente ebusitanos, como Na Guardis, o yacimientos con una marcada influencia púnica (Es Trenc y el Turó de ses Abelles). En la generación de los datos documentales de referencia para el nuevo paradigma interpretativo también son importantes las labores de prospección que se realizaron en los islotes de Mallorca y la documentación de la presencia púnica en muchos de ellos (Guerrero, 1981). 
Si bien es cierto que los trabajos de Mayoral ya proponen un contacto de tipo asimétrico donde las comunidades indígenas estarían en una posición de desigualdad (Mayoral, 1984a: 1306), no lo es menos que la construcción del modelo, tanto por su profundidad conceptual como por su argumentación arqueológica, se debe al amplio conjunto de publicaciones que, a lo largo de la década de los ochenta y los noventa, realiza Guerrero (1984a, 1984b, 1985, 1986, 1987, 1989, 1991, 1992, 1997, 2004), que a través de estos trabajos se convierte en el máximo exponente y defensor del discurso colonialista.

Conceptualmente hablando, la construcción de este modelo colonial bebe de diferentes fuentes, no siempre armónicas entre sí, pero que desde un punto de partida ecléctico permitieron la utilización y combinación de una serie de conceptos que estructuraron su propuesta. El modelo formulado, aunque Guerrero utilizó indistintamente el término colonial y colonización, estaría más cerca, siguiendo a Dietler $(1997,2009)$, de prácticas colonialistas que de una colonización propiamente dicha. ${ }^{6}$

Entre los conceptos clave que Guerrero utiliza para armar el modelo, tienen un papel fundamental:

a) La vinculación con las propuestas que caracterizan el modelo colonial bajo una relación dialéctica de centro-periferia (Rowlands et al., 1987; Champion, 1989; Wagner, 1993).

b) La utilización de referentes con una marcada visión economicista. Entre ellos destacan las referencias a Amin (1975, 1976, 1997). Estas relaciones asimétricas vendrían dadas por un tipo de comercio donde, siguiendo a Wagner (1993), las diferentes escalas de valor otorgadas a los bienes intercambiados (materias primas versus productos manufacturados) generarían profundas relaciones de desigualdad.

c) La utilización, en un primer momento, de algunas de las aportaciones de Polany $(1975)^{7}$ que permiten armonizar la escasa presencia territorial púnica en Mallorca con un modelo economicista de relaciones desiguales basadas en un comercio sin necesidad de ocupación territorial a partir de la idea de port of trade (Guerrero, 1982: 227, 1984: 9).

d) En esta relación asimétrica y desigual, las comunidades indígenas tendrán un papel pasivo, sin que se las dote de ninguna capacidad de agencia. Según estos autores las comunidades indígenas quedaron totalmente vinculadas a las decisiones que tomaron las comunidades púnico-ebusitanas, tanto en el tipo de comercio que se generó como en las influencias que recibieron.

6. Colonización entendida como el conjunto de prácticas que supone una dominación política sobre unos territorios y unas comunidades generada por agentes externos. Colonialismo, como conjunto de prácticas de control llevadas a cabo por agentes externos que generan relaciones de poder asimétrico entre las comunidades en contacto, así como todos los procesos que se derivan de ellas (Dietler, 2009).

7. En esta primera fase, Guerrero utiliza de modo parcial las aportaciones de Polany, puesto que enfatiza solo alguna de sus ideas como la de port of trade, que le permite encajar el modelo colonialista de base economicista con los datos arqueológicos que maneja. Con posterioridad, incorporará nuevas lecturas de Polany (Guerrero, 1997), especialmente a la hora de valorar el contacto y los intercambios entre sociedades urbanas y monetarias con comunidades no monetarias ni urbanas (Guerrero, 1992: 486). 
Algunas citas extraídas de los trabajos de Guerrero de los años ochenta nos permiten ilustrar lo que estamos comentado:

... las motivaciones que impulsaron a gentes semitas venidas de Ebusus a establecerse en tierras mallorquinas habrá que buscarlas necesariamente en términos económicos (Guerrero, 1992: 227).

La utilización de enclaves costeros no es casual y en su selección pudieron actuar los mecanismos que, a pequeña escala, plantea Polany para lo que denominó port of trade. Es decir, asentamientos que servían de contacto y control entre dos culturas con instituciones económicas diferentes; en este caso, unas comunidades indígenas no mercantilistas, la sociedad talayótica y una cultura urbana con una casta de comerciantes y artesanos profesionalizados, la púnico ebusitana (Guerrero 1982: 227).

En cuanto a documentación arqueológica, este modelo colonial se basó en los argumentos siguientes (Guerrero, 1984a y b, 1986, 1997):

El primero de ellos y más importante es que Guerrero, rompiendo con el modelo anterior que defendía un tipo de relación comercial, entiende que los contactos con el mundo púnico no se generan a partir «de la presencia de navegantes que como un punto más dentro de la ruta habitual de navegación recalasen en nuestras costas aprovechando tal circunstancia para establecer un comercio ocasional con los indígenas isleños» 8 (Guerrero, 1984a: 204), sino que «la clave a nuestro juicio radica en separar el fenómeno colonizador entendiendo como tal la presencia permanente con la fundación de enclaves fijos, más o menos importantes pero duraderos» (Guerrero, 1984a: 204). Prueba de ello era, según Guerrero, la fundación de factorías costeras por parte de los ebusitanos, entre las que destacaría Na Guardis y otros islotes costeros como Na Galera o Illot d'en Sales, todos ellos situados al sur de Mallorca.

Un segundo argumento se relacionaba con la existencia de un control territorial de los recursos estratégicos por parte de los púnico-ebusitanos. La documentación de yacimientos como Es Trenc (Guerrero, 1987) y la explotación de las salinas por parte de agentes ebusitanos (Guerrero, 1984a, 1986, 1997) reforzarían documentalmente este segundo argumento.

El tercer argumento se basaba en la existencia de un intercambio de tipo desigual. Siguiendo el modelo de relación metrópolis/colonia o centro/periferia se proponía que el tipo de intercambio consistiría en la aportación de materias primas por parte de las comunidades indígenas a cambio de productos elaborados procedentes de la "metrópolis» ebusitana.

Este comercio de ultramar pivota sobre dos ejes básicos, control y explotación de las materias primas indígenas y la introducción al por mayor de productos elaborados entre las comuni-

8. Tal y como proponían en la fase anterior (nota de los autores). 
dades talayóticas, principalmente aceite, vino, posibles salazones que se complementan con instrumentos metálicos, vajilla cerámica a torno y otros abalorios de carácter suntuario... (Guerrero, 1984b: 9).

El cuarto y último argumento que demostraría una relación asimétrica y desigual sería la explotación, por parte del mundo púnico, de los recursos humanos a partir de la existencia de levas y utilización de mercenarios baleáricos dentro de los ejércitos cartagineses 9 (Guerrero, 1984a, 1986, 1997).

Estos cuatro argumentos se mantendrán prácticamente inamovibles a lo largo de toda esta etapa, tanto en sus primeras formulaciones como en sus propuestas más matizadas.

En esta primera etapa de desarrollo del modelo colonial (1979-1992), junto al carácter propio de los contactos, también se pone un gran énfasis en las consecuencias que tuvieron para las comunidades indígenas.

En primer lugar, Guerrero incide en los mecanismos de contacto entre ambos grupos de comunidades a partir de tres ejes:

a) La salida y vuelta de los mercenarios y su convivencia prolongada con pueblos protohistóricos (etruscos, campanos, iberos, libios, númidas) del Mediterráneo occidental (Guerrero, 1982: 211 y ss., 1986: 340, 1985: 89).

b) La presencia de asentamientos púnicos en Mallorca (1982, 1984a, 1985).

c) En un momento posterior, Guerrero (1992: 489) incorpora una tercera vía de aculturación que consiste en la presencia indígena en las tareas de apoyo directo de los colonos asentados en los yacimientos costeros, tales como la explotación de la sal y las actividades de redistribución a pequeña escala que proporcionarían unas excelentes ocasiones de convivencia con los mercaderes y marinos púnicos.

Todo ello generaría una profunda modificación en cada uno de los ámbitos que configuraban las comunidades indígenas (Guerrero, 1984a y b, 1985, 1986), especialmente en los planos religioso y funerario. En este sentido, muchos de los fenómenos que dentro de este ámbito caracterizan las comunidades postalayóticas fueron interpretados como el resultado de procesos de influencia y aculturación púnica. Entre ellos, podríamos citar: el uso de urnas funerarias, parihuelas y ataúdes, la inhumación en cuevas hipogéicas, los enterramientos en cal, la construcción de santuarios, ${ }^{10}$ las prácticas de incineración, las manifestaciones iconográficas de escultura en bronce asociadas con el culto a Reshef/ Melkart, aunque bajo cánones estéticos helenizantes, etc. En otros planos, ya fuera del ámbito funerario, también se enfatiza el papel de la influencia púnica en la "imitación» de formas cerámicas púnicas fabricadas manualmente, o en la aparición de asentamientos y factorías indígenas que funcionarían como agentes distribuidores de productos púnicos

9. Para un análisis sinóptico del fenómeno, consúltese Domínguez Monedero (2004).

10. Así como la presencia en ellos de monolitos interiores que se vinculan con el DJED o columna sagrada oriental. 


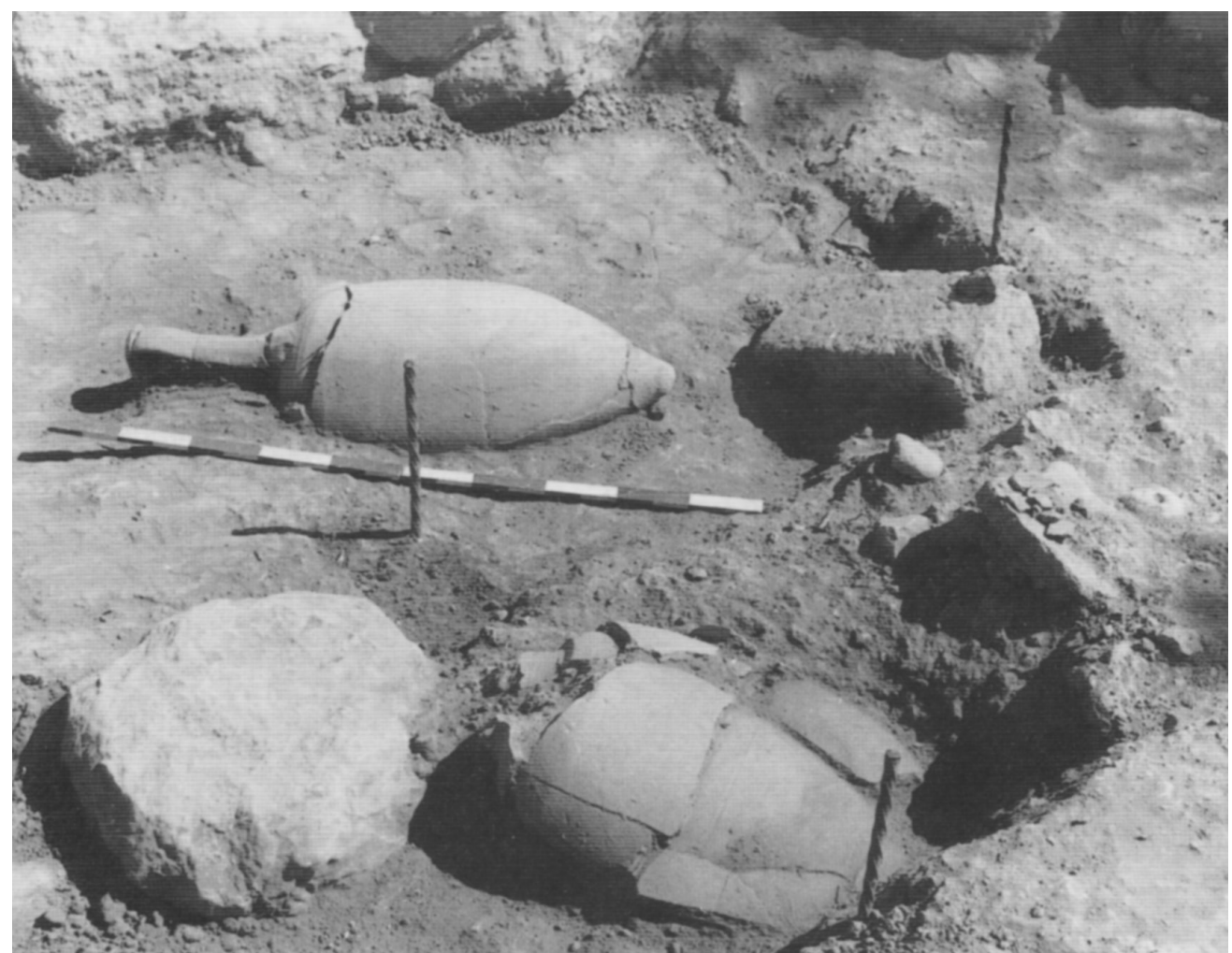

Figura 3. Excavación del yacimiento del Turó de ses Abelles en los años 1970 (Camps y Vallespir 1998).

y romanos. En este discurso tendrá un papel protagonista el yacimiento del Turó de ses Abelles (fig. 3):

... algunas comunidades indígenas se muestran especialmente dinámicas y llegan a fundar establecimientos en los que se reproducen en gran medida las actividades y los fines de las factorías comerciales púnicas como el Turó de ses Abelles. Este protagonismo en el plano comercial de las gentes talayóticas no se puede explicar sin tener en cuenta el acicate que debió suponer la proliferación de pequeños enclaves comerciales (púnicos) ${ }^{11}$ a lo largo de la costa (Guerrero, 1984b: 28).

Según Guerrero (1994), este intercambio desigual y cada uno de los cambios que de él se derivan tendrá como consecuencia final la descomposición creciente de la estructura social postalayótica, inicialmente organizada sobre vínculos de parentesco, que irá siendo sustituida por una sociedad en la que primará la dependencia personal.

11. Nota de los autores de este trabajo. 
En definitiva, todo este planteamiento concebía las comunidades indígenas como meros elementos receptivos y completamente pasivos que, junto a una visión economicista y asimétrica del fenómeno, conformaron las bases del discurso. Una última cita nos permite reflejar de manera clara este posicionamiento:

... nos preguntamos hasta qué punto este status de subdesarrollo tecnológico fue intencionadamente provocado por los colonizadores que, en ningún caso, estarían dispuestos a perder un mercado indígena para sus productos cerámicos (Guerrero, 1984a: 212 y 1984b: 22).

\subsection{La reformulación del modelo colonial y el papel activo otorgado al mundo indígena (1992-2009)}

En 1987 se produce un hecho que marcará un cambio importante en las praxis arqueológicas de las islas Baleares: la paralización de buena parte de las intervenciones programadas por parte de la Conselleria de Cultura para potenciar la redacción de las cartas arqueológicas de los diferentes municipios de las islas. Esto supuso, en gran medida, la paralización de proyectos y excavaciones; entre ellas, y de manera significativa para el caso que nos ocupa, el del asentamiento ebusitano de Na Guardis. Con dicha paralización se produjo un cambio de personas, instituciones y praxis arqueológicas, puesto que, cuando se volvieron a poner en marcha las líneas de subvenciones para el desarrollo de excavaciones programadas, a partir de 1995, habían cambiado los modelos de excavación, los principales directores de proyectos arqueológicos y se habían ampliado las técnicas analíticas disponibles. Sin embargo, ambos elementos no pueden entenderse como una simple relación de causa y efecto.

Entre los años que van de 1987 a 1995 se generó un profundo cambio en la concepción de la arqueología mallorquina en la que influyeron, entre otros aspectos, elementos como el traspaso de competencias en temas de patrimonio histórico del Govern Balear a los Consells Insulares, la reubicación profesional de arqueólogos, la aparición de nuevas praxis arqueológicas como la arqueología comercial, o la concepción integral de los proyectos arqueológicos donde las praxis de excavación se asociaron, indivisiblemente, a las de valorización y sociabilización del bien. Por otra parte, y ya centrándonos en el tema que nos ocupa, no podemos dejar de lado el hecho de que en 1992 Guerrero se incorpora a la Universidad de las Islas Baleares y se adscribe al Área de Prehistoria. Esta situación, así como la necesidad de adaptar su currículo científico a un nuevo perfil, mucho más vinculado con la prehistoria, influyó de manera determinante en la matización del modelo colonial planteado a principios de los años ochenta.

Otro hecho que contribuyó, a la larga, a la progresiva valorización de la comunidades locales fue la vuelta en 1994 de un equipo de la Universidad de Barcelona liderado por Jordi Hernández y Joan Sanmartí (Hernández et al., 1998, 1999) a las excavaciones de las necrópolis postalayóticas de Son Real y la Illa des Porros. La excavación de estos yaci- 
mientos funerarios había sido ya iniciada entre los años 1957 y 1962 por Miquel Tarradell (Hernández, 1998) y había quedado paralizada durante más de treinta años.

Sin embargo, y a pesar del paro forzoso debido a la falta de financiación de la Conselleria de Cultura, la producción científica en relación con el estudio del fenómeno colonial siguió siendo amplia y claramente liderada por Víctor Guerrero, que poco a poco va introduciendo matices y puntualizaciones en el modelo inicialmente propuesto.

El primero de los elementos que dará paso a una matización del modelo colonial que se había propuesto a principios de los ochenta debe relacionarse con las críticas que recibió por parte de autores como Coll (1989) y Gornes et al. (1992). Si bien ninguno de ellos rompe con los ejes conceptuales del modelo basado en la existencia de una relación asimétrica y desigual, difieren sustancialmente en cuanto a la intensidad e influencia que tuvieron dichos contactos. En este sentido, Coll (1989: 673) pone el énfasis en que muchas de las expresiones funerarias (presencia de ataúdes, inhumación en cal o utilización de cuevas hipogeas) no tienen su origen en un contacto con los púnicos, oponiéndose a las tesis de Guerrero (1986), sino en las propias dinámicas internas de las comunidades locales. Por su parte, Gornes et al. (1992) entienden que los datos no permiten plantear la existencia de una colonización propiamente dicha, sino que la presencia ebusitana en las Baleares no pasaría nunca de un estadio precolonial, pues no había voluntad de ir más allá. Según estos autores, la prioridad de los ebusitanos era, exclusivamente, la de convertirse en hegemónicos en las demandas comerciales de los isleños. Como contrapartida, los isleños aportarían al intercambio, casi de manera exclusiva, personas que irían a engrosar, como mercenarios, los ejércitos púnicos. Finalmente, y quizás es en este aspecto donde se marcan más claramente las diferencias, estos autores rompen con el planteamiento general de una amplia influencia púnica en todos los ámbitos de las comunidades postalayóticas, especialmente en el plano religioso-funerario. Entienden que muchos de los fenómenos observados se explicarían mejor desde una evolución interna que desde el prisma de la aculturación y la asimilación ideológica y cultural.

En paralelo, Hernández-Gasch y Sanmartí $(1999,2003)$ empiezan a plantear tímidamente la existencia de un refuerzo de la identidad a través del incremento de la actividad ritual de las comunidades indígenas ante las amenazas externas fruto del incremento de los contactos coloniales y la presencia romana en la isla a partir de los siglos II-I aC. Dicho discurso será ampliado a todo el período colonial balear por Hernández-Gasch en 2009, dando un papel más relevante y mayor autonomía a las comunidades indígenas, pero insistiendo en que dichos cambios son producto de los intensos contactos comerciales púnicos.

Fruto de estas críticas, Guerrero inicia un largo proceso de matización y reorientación de algunos de los elementos que caracterizaban su modelo, en especial, de aquellos que se refieren a la influencia que tuvo el contacto con el mundo púnico en la evolución y transformación de las comunidades postalayóticas. Paradigmática es, en este sentido, la siguiente cita textual de Guerrero «... las cuestiones sobre aculturación indígena eran en realidad hipótesis o líneas de trabajo que convenía abrir y profundizar, pero no conclusiones acabadas como, exageradamente, han interpretado algunos investigadores. Muchos 
aspectos tratados en él pueden mantenerse, aunque otros han sufrido oportunas y fundadas correcciones" (Guerrero, 1993: 463). Sin embargo, admitiendo lo anteriormente apuntado, entiende que «es cierto que supondría un análisis simplista interpretar todos los cambios que ocurren en la cultura talayótica (y sobre todo los que afectan al plano de las transformaciones ideológicas) bajo la óptica cultural púnica, negando toda capacidad de recreación a la cultura indígena, pero no es menos cierto que estos cambios se producen por el estímulo colonial púnico que agiliza la dinámica evolutiva endógena de la sociedad talayótica» (Guerrero, 1993: 465). En la misma línea se sitúa en 1997 cuando publica el libro La colonización púnica de Mallorca, obra que sintetiza toda esta línea de trabajo. En él se argumenta que «no creemos que el factor colonial cambiase sustancialmente la formación social talayótica que en ningún momento traspasa el nivel organizativo de jefatura tribal, a lo que sí contribuyó la colonización fue a intensificar algunas tendencias ya presentes en la precolonización, entre ellas, el poder coercitivo de la jefatura, la jerarquización social, el desarraigo de algunos grupos y la aparición o el incremento de formas de dependencia personal» (Guerrero, 1997: 303).

En cualquier caso, y de manera paralela a estas matizaciones que suponen la incorporación de un tímido nivel de agencia a las comunidades indígenas, se mantiene firme en la defensa de un modelo colonial y la existencia de relaciones asimétricas: "Me resulta difícil admitir la tesis planteada sobre la inexistencia de una colonización efectiva sin que el proceso fuese más allá de un estadio precolonial... La existencia misma de Na Guardis y otros yacimientos subsidiarios de tipo permanente, aunque seguramente de uso estacional, apuntan a la existencia de un fenómeno colonial» (Guerrero, 1992: 485), o "confirmada de forma irrefutable la existencia de una colonización prerromana de Mallorca es llegada la hora también de matizar las peculiaridades concretas que la distinguen de otros procesos coloniales» (Guerrero, 1993: 465).

Un segundo factor que influyó de manera decisiva en la evolución y matización del modelo fue la misma evolución personal de Guerrero a la hora de enfocar el fenómeno. En ello tuvo un papel fundamental el proyecto de investigación y excavación que se viene desarrollando desde 1996 en el Puig de sa Morisca y del cual fue director hasta su baja forzada por enfermedad en 2009. A través de este proyecto, se contribuyó al análisis de los contactos coloniales, no ya desde la perspectiva de las comunidades púnicas, sino a partir de la perspectiva de las comunidades autóctonas.

Fruto de lo anteriormente comentado, a lo largo de la primera década del siglo XxI, se va a reconfigurar el modelo colonial a partir de los siguientes puntos:

a) Se realiza un rearme teórico a partir de las referencias a autores como Frankenstein (1997) y su caracterización del modelo colonial. Dicho modelo, si bien sigue en gran medida la propuesta colonial anterior, se sustenta sobre dos aspectos básicos: la presencia de uno o más grupos de gente extranjera en una región situada a cierta distancia y la evidencia de explotación socioeconómica o relaciones de dominio sobre la población colonizada (generalmente mayoritaria). En consecuencia, y según este 
planteamiento, el colonialismo se referiría a relaciones de poder (más que a movimientos de personas) y a relaciones de dominación entre colonizador y colonizado (Guerrero, 2004a y b, 2006; Guerrero et al., 2002, 2007).

b) Una revisión profunda de las etapas del fenómeno, con la identificación de tres fases: fase de comercio aristocrático o modelo de contacto no hegemónico, fase de comercio empórico o modo de contacto sistemático, siguiendo los modelos de Alvar (1999) y López Castro (2000), y una última fase denominada modelo mixto, donde convivirían las factorías púnicas con los centros de transformación y redistribución indígena (Guerrero et al., 2002, 2007).

c) Una introducción de los análisis cuantitativos anfóricos con el fin de evaluar la intensidad de los intercambios (Guerrero y Quintana, 2000; Quintana y Guerrero, 2004; Quintana, 2000, 2006; Guerrero, 2004b).

d) Una redefinición de los argumentos arqueológicos que sustentaban el modelo inicial y que se pueden sintetizar en los siguientes postulados (Guerrero, 2006a y b; Quintana y Guerrero, 2004; Guerrero et al., 2002; Calvo et al., 2009):

1) Fundación de un asentamiento extranjero en Mallorca, Na Guardis.

2) Explotación industrial de las salinas del sur de Mallorca, lo que implica la utilización de mano de obra indígena sometida, así como su gestión directa a cargo de agentes púnicos.

3) Prestación de servicio de armas en las filas de los ejércitos coloniales en forma de levas.

4) Redistribución de los productos púnicos a partir de redes indígenas; esta segunda escala de redistribución, probablemente hacia los poblados del interior de Mallorca, ya estaría en manos exclusivas de las comunidades postalayóticas.

En definitiva, si bien la reformulación del modelo mantiene la idea de la existencia de una relación asimétrica entre las comunidades púnicas y las postalayóticas, se subraya la presencia de un mayor protagonismo y agencia de las comunidades autóctonas, que se concreta, entre otros elementos, en las mismas dinámicas que caracterizarían la fase de comercio no hegemónico y en la capacidad de redistribución hacia el interior de algunos asentamientos indígenas, o en el protagonismo de las comunidades locales en el funcionamiento de algunas factorías indígenas como el Turó de ses Abelles.

\section{Matizaciones, revisiones y búsqueda de nuevos modelos (2009-2017)}

La reflexión y la revisión de las narrativas en torno a los contactos entre las comunidades púnicas e indígenas en la Mallorca de la segunda Edad del Hierro no han supuesto, a día de hoy, la generación de una nueva propuesta que sustituya la anterior. En realidad, estamos ante un profundo proceso de revisión y reflexión que aún no ha generado un consenso acerca de un modelo interpretativo alternativo. 


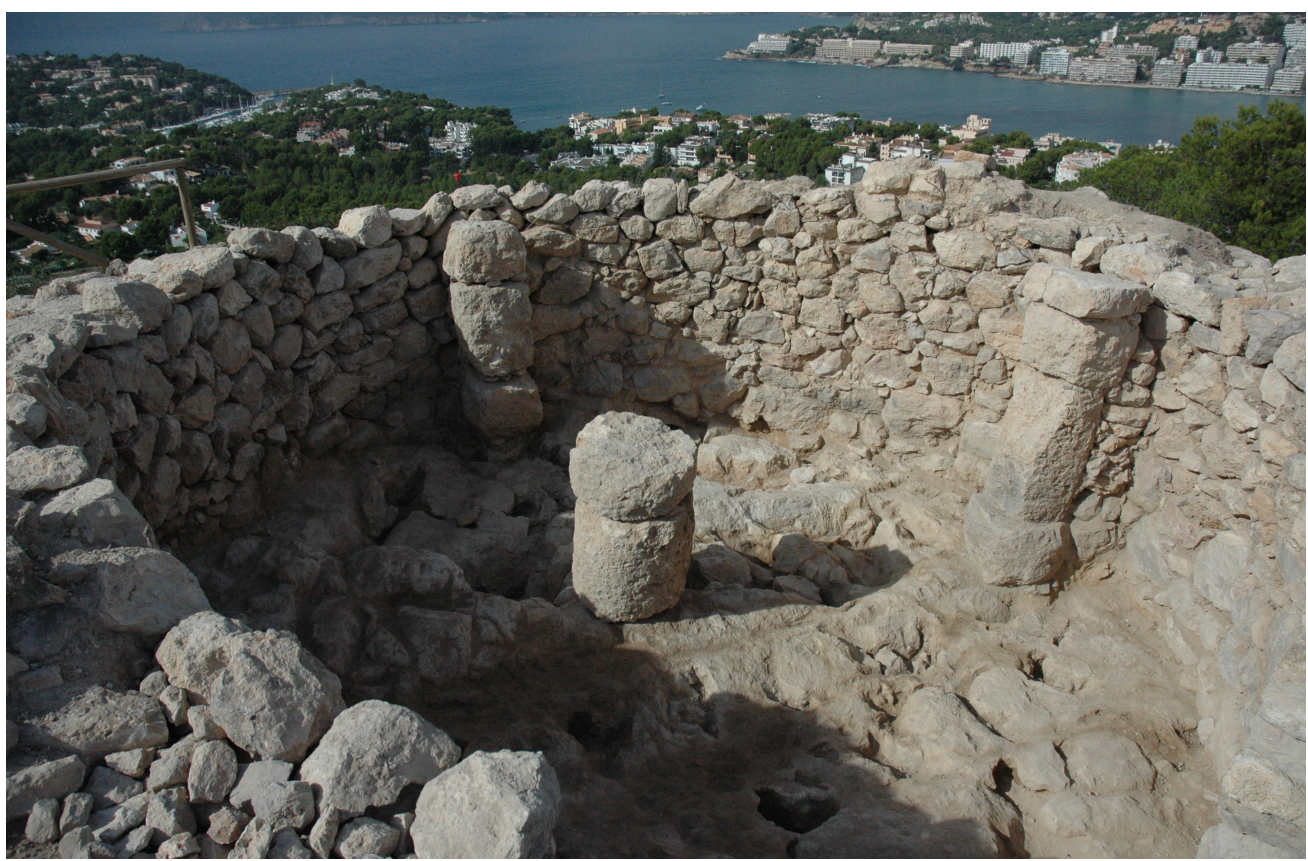

Figura 4. Puig de sa Morisca, la Torre III situada en la cima de la colina.

Sin embargo, debemos tener en cuenta algunos elementos a la hora de contextualizar e interpretar los cambios que en las narrativas propuestas se están dando en esta última década.

En primer lugar, debemos tener en cuenta que en Mallorca, a partir de 2005, se produce un incremento significativo de la excavación y publicación de importantes niveles de ocupación correspondientes a la segunda Edad del Hierro. Se continúa con las excavaciones de yacimientos de habitación como el Puig de sa Morisca (fig. 4), Hospitalet, Son Fornes, o Ses Païsses, o necrópolis como la de Son Real, pero se incorporan nuevos proyectos como la excavación del turriforme escalonado de Son Ferrer (Calvià), el poblado de Bochoris (Pollença), el turriforme de Mestre Ramon (Son Servera) o la Cova des Diners (Sencelles). Más recientemente, y de manera paralela, se inicia la excavación del asentamiento púnico en el islote de Na Galera y un nuevo programa de prospecciones de islotes costeros por parte de Carlos Quintana.

El aumento de excavaciones programadas debe relacionarse con la ampliación del programa de subvenciones por parte del Consell Insular, que, si bien dista aún de alcanzar una situación aceptable, ha permitido incorporar a nuevas personas y equipos desvinculados de los centros académicos universitarios.

Ello, unido a los proyectos que provienen de universidades como la UIB, la UAB o la Universidad de Washington, ha supuesto una clara revitalización del panorama arqueológico mallorquín para este período. 
En segundo lugar, esta fase se caracteriza por la desgraciada baja profesional del profesor Víctor Guerrero en 2009 y el abandono de su carrera investigadora, debido a una enfermedad crónica que le impidió continuar con sus investigaciones y seguir formando a futuros arqueólogos. En este sentido, las propuestas en las que estaba trabajando y que suponían un avance en los modelos que había planteado no han podido materializarse.

En definitiva, lo acontecido desde 2005 ha supuesto un cambio radical en muchos de los agentes y praxis, que sin duda han favorecido la situación de revisión de modelo que se está dando en la actualidad.

Ya desde un punto de vista más internalista epistémico, esta última fase se caracteriza por una profunda revisión y crítica del modelo colonial. Encontramos las primeras referencias en dos trabajos, García Rosselló (2010) y Calvo y Guerrero (2011), donde se revisa el fenómeno de la colonización y se plantean conceptos de resistencia por la parte indígena, centrados en la ausencia de escritura, industria del torno o moneda, entre otros.

A grandes rasgos, se pueden establecer las críticas y revisiones al modelo colonial a partir de los siguientes ejes: a) En lo teórico y conceptual, con una profunda crítica a los modelos coloniales, la ocupación territorial y el énfasis en los contactos asimétricos o desiguales en la línea que aportan las tendencias postcoloniales. b) En cuanto a estrategia de estudio, con un análisis mucho más profundo de los datos y los contextos arqueológicos, con el desarrollo de estrategias de estadística cuantitativa y de análisis de microcontextos.

\subsection{Crítica al discurso y modelo colonial e incorporación de nuevas herramientas interpretativas derivadas de los postulados postcoloniales}

La crítica al modelo colonial anterior parte de cuatro ejes básicos, todos ellos muy enraizados con la línea interpretativa postcolonial (Van Dommelen, 1998, 2000, 2006; Rowlands et al., 1987; Dietler, 2009).

El primero de los ejes de esta crítica se centra en la oposición frontal a la idea defendida por los modelos coloniales o colonialistas sobre las relaciones asimétricas de desigualdad entre púnicos y comunidades indígenas de la segunda Edad del Hierro. En ellas unas comunidades, las púnicas, establecerían las normas, los productos de intercambio y las estrategias, mientras que las otras comunidades, las postalayóticas, quedarían relegadas a un papel más pasivo y con una agencia reducida o nula. Este patrón de relaciones desiguales y de dominación hunde sus raíces en las justificaciones filosóficas y en los paradigmas interpretativos que fueron utilizados para analizar y justificar el modelo colonial europeo del siglo xix y que se habían trasladado a la antigüedad y a la prehistoria, donde se detectaban situaciones con presencia de uno o varios grupos fuera de su región de origen. Se trata de un modelo interpretativo influenciado por una ideología economicista que concibe las relaciones entre indígenas y foráneos desde una perspectiva jerárquica y en la que la 
separación entre unos y otros está perfecta y falsamente delimitada (Van Dommelen, 1998; Dietler, 1995, 2009; Stein, 2005; Vives Ferrándiz, 2005; Delgado, 2008).

Desde las nuevas propuestas, se defiende que la perspectiva anterior desarrolló una imagen contrapuesta, dual y esencializada del colonizador frente al colonizado, sin la posibilidad de la existencia de situaciones intermedias (Said, 2003; Bhabha, 1994). Con ello, se instrumentalizaba la generación del conocimiento con el fin de legitimar la dominación. El resultado, en cuanto a su interpretación, representa enfatizar las diferencias, desde una perspectiva occidental, entre dos bloques monolíticos, uniformes y opuestos, lo occidental (nosotros) y lo no occidental (los otros). Estos últimos son percibidos de manera despectiva, como algo inferior y subordinado. De este modo se construye la identidad del «otro» de manera artificial, representada como algo homogéneo e inmutable, que es a su vez indisoluble a la identidad del yo — nosotros occidentales-, por lo que no cabe su existencia sin la contraposición de ambas identidades (Hernando, 2006).

Las nuevas propuestas pretenden romper con la existencia de estos dualismos, de dos identidades antagónicas (colonizador-colonizado, dominante-sometido, primitivoevolucionado, etc.), e insistir en la necesidad de contextualizar caso por caso aquellas situaciones en las que se documenten grupos desplazados a un área geográfica distinta de la de origen; así, desaparecen las generalidades universales y se busca la complejidad del caso, con la existencia de variedades y situaciones ambiguas.

Desde este punto de partida, diferentes autores (García Rosselló, 2010; Calvo y Guerrero, 2011; Hernández y Quintana, 2013; Calvo et al., 2014; Albero, 2017; Perelló, 2017; García Rosselló y Calvo, 2018) inciden en que en los contactos que se establecen entre comunidades púnicas y postalayóticas participan diferentes escalas de valores, por lo que el análisis exige romper con visiones duales que inducen a un esencialismo, intentando, por el contrario, abrir el abanico interpretativo a una multiplicidad de perspectivas. La idea inicial de que el intercambio favorece a unos sobre otros (obtención de materias primas a cambio productos elaborados) no refleja la realidad del proceso, puesto que, al estar ante diferentes escalas de valor, la recepción de productos de difícil acceso en el entorno social de las comunidades autóctonas pudo influir en que el interés y el beneficio del intercambio fuese mutuo y aceptado como válido por ambas partes. Bajo este prisma, desaparecería la asimetría y nos moveríamos en unos parámetros de igualdad, con situaciones intermedias, espacios ambiguos y praxis híbridas en las que participarían ambas comunidades.

El segundo eje de la crítica al modelo colonial se centra en la consideración del papel pasivo de las comunidades postalayóticas, conceptualizadas en el modelo anterior como meros receptores, con una baja capacidad de agencia o intervención. Ello afectaría tanto a los productos que se intercambian como al modelo de contacto que se desarrolla o a las influencias que reciben. Frente a esta postura, se incide en el papel activo de las comunidades indígenas. Dicha agencia se concreta en cada uno de los campos de análisis, tanto en el modelo de contacto que se establece como en la relación y los intercambios que se realizan o en cómo dichas comunidades reciben y reinterpretan los objetos y elementos 
ideológicos que se intercambian. En este sentido, es ilustrativo el papel central que se otorga a las comunidades postalayóticas a la hora de interpretar los procesos de redistribución hacia el interior de la isla de Mallorca ${ }^{12}$ (Hernández y Quintana, 2013) o el papel activo que ejercen dichas comunidades a la hora de seleccionar los objetos que se intercambian o la manera en que las comunidades indígenas reinterpretan los objetos importados, introduciéndolos en prácticas propias y dando lugar a diferentes fenómenos de hibridación (Calvo et al., 2015; Perelló, 2017; García y Calvo, 2018).

Encontramos un ejemplo de estos planteamientos en Hernández y Quintana (2013: 322):

En ausencia de ocupación territorial, las comunidades autóctonas debieron de tomar un rol activo en la redistribución de bienes importados si, según parece, el contacto directo entre ebusitanos y las poblaciones baleáricas se limitó a lugares relativamente cercanos a la costa. Apoyan esta idea las grandes cantidades de ánforas halladas en los yacimientos más costeros y su decrecimiento hacia el interior, tendencia constatada en el curso de las excavaciones y prospecciones arqueológicas mencionadas.

En esta misma línea, se rompe con la idea de tratar las comunidades en contacto como bloques homogéneos, monolíticos y contrapuestos. En este sentido, se incide en la existencia de comunidades indígenas que tienen roles distintos en relación con los grupos, materiales e ideas de origen púnico. Dentro de este marco, cada vez se es más consciente de la imposibilidad de colocar en el mismo grupo todas las comunidades postalayóticas de la isla de Mallorca. Se ve una marcada diferencia entre las que se ubican en la costa y las de interior. Y entre las costeras se observan diferencias entre las que se localizan en zonas de amplia penetración de material púnico al sur de la isla (Santa Ponça y Colònia de Sant Jordi) y las que se sitúan en otras zonas costeras como el levante o norte insular (Hernández y Quintana, 2013; Calvo et al., 2014; García Rosselló y Calvo, 2018; Quintana, 2018).

El tercer eje crítico se centra en una revisión de las bases documentales sobre las que se asentaba el modelo colonial (Hernández y Quintana, 2013; Ramon, 2017; Quintana, 2018). En primer lugar, se incide en que el dominio territorial que se había propuesto es muy fragmentario y se circunscribe al uso de algunos islotes. En esa misma línea, se critica y limita mucho la explotación de las salinas por parte de los púnico-ebusitanos y la participación de la población autóctona en estas prácticas. La revisión de los datos ha puesto en evidencia que, más allá de la presencia testimonial de algún resto, la explotación de las salinas de la zona de Es Trenc se desarrolló, principalmente, durante época romana, por lo que la defensa de una explotación tanto de recursos como de personas durante la segunda Edad del Hierro tiene un difícil encaje con la realidad documental arqueológica, más allá de una frecuentación esporádica, que sin lugar a dudas existió.

12. En cualquier caso, se debe tener en cuenta que algunos de estos aspectos ya se habían ido apuntando en la fase anterior, en especial el papel que algunas comunidades desarrollaron en relación con los procesos de redistribución de productos de origen púnico (Guerrero et al., 2002, 2007) o el papel activo en la definición de los elementos de intercambio (Guerrero et al., 2002). 
La ausencia de una ocupación territorial de las Baleares por elementos púnicos es un hecho arqueológico e histórico. Lo refuerza el que la base ebusitana de Na Guardis pueda ser considerada un asentamiento estacional (Hernández y Quintana 2013: 321).

\subsection{El análisis de la intensidad y de los tipos de contacto y de cómo estos se generaron}

Durante estos años se ha incidido en el análisis del modelo de intercambio, especialmente a partir de los estudios anfóricos. En esta línea se ha trabajado en analizar, cuantitativamente, el nivel y el vigor de la recepción de material anfórico entre las comunidades ebusitanas y las postalayóticas (Hernández y Quintana, 2013; Gelabert, 2013, 2014; Quintana, 2006, 2015). Fruto de este análisis se ha podido ver como el flujo de la recepción del material anafórico varía a lo largo de la segunda Edad del Hierro. A su vez, se ha constatado que este intercambio es mucho más limitado, al menos cuantitativamente hablando, de lo que antes se pensaba. En este sentido, diferentes estudios realizados a partir del análisis del número mínimo de individuos anfóricos por metro excavado de yacimiento (Hernández y Quintana, 2013) o el cálculo, a partir del NMI, de la cantidad de vino consumido en un poblado por año (Gelabert, 2013, 2014), refleja que la presencia de ánforas, especialmente vinarias, era muy limitada. Sin embargo, ello no excluye que estos productos ejerciesen un papel cualitativamente importante e influyente en las praxis de las comunidades postalayóticas.

Más allá del análisis de intensidad de tipo cuantitativo, también se está desarrollando un estudio profundo de los contextos indígenas donde la materialidad local interactúa con la foránea. A la hora de enfrentarse a este complejo fenómeno, el modelo tradicional de aculturación ha dejado de percibirse como útil para describir las situaciones resultantes de los contactos entre comunidades. Frente a ello, se han ido incorporando nuevos conceptos utilizados por las corrientes postcoloniales que se ajustan mejor a los objetivos que actualmente se están planteando. Entre ellos, destaca la utilización y análisis de conceptos como el de hibridación, espacios liminares o intermedios, mymicry o appropiation (Bhabha, 1994; Van Dommelen, 1997; Dietler, 1997; Vives Ferrándiz, 2005; Delgado, 2008). De esta manera, se profundiza en el estudio de las situaciones de contacto y la manera en que los objetos e ideas foráneas son recibidas y reconceptualizadas por las comunidades locales incorporando nuevos significados que no suponen, necesariamente, la autoexclusión de los anteriores, sino que se va generando un proceso complementario de resignificación. Estos conceptos interpretativos permiten poner en evidencia el carácter multidireccional, heterogéneo y en continua transformación que adquieren los contactos entre las sociedades. En esta línea se ubican los trabajos de García Rosselló (2010), Calvo et al. (2014), Albero (2017), Perelló (2017), García Rosselló y Calvo (2018).

Frente a esta tendencia historiográfica mayoritaria, que supone una revisión de los modelos coloniales y que insiste en reenfocar el tema, evitando el uso de asimetrías a la 
hora de concebir las relaciones entre las comunidades púnicas e indígenas, no podemos dejar de citar un trabajo reciente de Ramon (2017) que, a partir de una profunda y muy documentada revisión de los materiales púnicos en yacimientos de Mallorca y Menorca y la reinterpretación de la ocupación de los islotes costeros, propone una nueva variante de un modelo colonial de relación asimétrica entre ambos grupos de comunidades. Para ello toma como referentes los modelos que se han utilizado para analizar la situación colonial europea entre los siglos XVI y XVIII (Duval, 1863: 401-405, en Ramon, 2017): "el llamado "pacto colonial" o "régimen de lo exclusivo", aplicado en la Edad Moderna por las metrópolis europeas a sus colonias de ultramar» (Duval, 1863, 401-405) presenta "algunas similitudes con la situación en las Baleares que son, como mínimo, sospechosas. Dicho pacto tenía como ejes básicos cinco puntos: mercado reservado a los productos manufacturados en la metrópolis, aprovisionamiento de la metrópolis en materias primas y alimentos de primera necesidad, monopolio de la navegación bajo "bandera nacional", prohibición a las colonias de reproducir sistemas industriales y cultivos similares a los metropolitanos, impuestos financieros sobre las mercancías en sentido bidireccional» (Ramon, 2017: 80).

La idea central que propone Ramon se basa en que Ebusus mantuvo para Mallorca y Menorca, entre la segunda mitad del siglo v aC y hasta al menos el final de la Segunda Guerra Púnica, un «mercado reservado» con un claro predominio de los mercaderes ebusitanos a la luz de los pecios conocidos: «... a los productos de Ibiza, en los cuales cabe, evidentemente, incluir también otros de origen no ebusitano, pero comercializados por agentes de esta isla, entre los cuales, evidentemente, vino ibérico. No están claras otras navegaciones comerciales en este lapso temporal por parte de otras entidades y el análisis de las evidencias arqueológicas realizado más arriba autoriza a hablar, no solo de una hegemonía comercial, sino de un verdadero monopolio ebusitano» (Ramón, 2017:80).

En combinación con esta línea argumental, se insiste en la idea de que las Baleares surtieron de productos a Ebusus, en especial de grano, y mercenarios y apunta la hipótesis de que la falta de evidencias de explotación de la vid en las islas mayores sería fruto de la prohibición de reproducir industrias y cultivos similares a los metropolitanos de Ebusus (Ramón, 2017: 80).

En definitiva, si bien el mismo autor plantea estas ideas como una hipótesis a tener en cuenta, propone mantener el concepto de colonización o al menos algo más que la simple relación comercial:

Qué todo ello se quiera traducir en términos de dominio y explotación dependerá también del punto de vista que se aplique; en todo caso, cabe no olvidar que las fuentes históricas son parcas y a veces confusas, mientras que las evidencias arqueológicas resultan complejas, aunque estas últimas, en determinados casos, parecen reflejar algo más que simples acciones de comercio (Ramón, 2017: 84).

Estos últimos años se nos presentan, en relación con el análisis de los contactos entre las comunidades púnico-ebusitanas y postalayóticas, como una fase de reflexión, rearme 
de nuevos modelo y defensa de las propuestas consolidadas. La diferencia entre ellos no parte tanto de la utilización de datos distintos, sino de puntos de partida teóricos diferentes, cuando no antagónicos. El resultado es la existencia de patrones diversos, con lo que se nos presenta para los próximos años un panorama interpretativo enormemente abierto.

\section{Conclusiones}

El análisis de las diferentes narrativas a lo largo de más de seis décadas de estudios sobre los contactos entre las comunidades púnico-ebusitanas y las comunidades autóctonas de la segunda Edad del Hierro en Mallorca ha puesto de evidencia cómo en su gestación ha sido tan importante el conjunto de datos arqueológicos de los que se disponía, como el contexto teórico y el paradigma de referencia de cada autor y de cada época. A su vez, es imposible desligar ambos elementos de las praxis científicas y contextos ideológicos y sociales que, en cada momento, se estaban desarrollando. En cierta manera, podríamos afirmar que las interpretaciones predominantes en cada período son, por ello, quizá tan deudoras de su propio tiempo como de los datos arqueológicos sobre los que se sustentaban.

Especialmente importante fue, en el devenir de las propuestas, la influencia que tuvo la introducción de un concepto como el de colonización por parte de Víctor Guerrero, que condicionó y sigue condicionando los discursos de estas últimas décadas. Como hemos visto, la construcción del modelo colonial a lo largo de los años ochenta y noventa, su matización durante la primera década del siglo XXI, así como su deconstrucción a partir del año 2010, han marcado claramente las narrativas y los discursos de estas últimas décadas. Sin embargo, es imposible entender este fenómeno analizando únicamente los datos arqueológicos con los que se contaba en cada momento, sino que se hace necesario combinarlo con el análisis del contexto científico y social de la época. En este sentido, la introducción del término colonización púnica de Mallorca por parte de Guerrero en 1984 se plantea en un contexto científico de auge del fenómeno colonial fenicio-púnico en el conjunto del Mediterráneo occidental. En especial, cabe destacar la influencia que tuvieron en ello figuras referenciales como Aubet y su trabajo de síntesis Tiro y las colonias de occidente (1987) o los trabajos sobre las colonias de levante de Wagner (1993), Alvar (1999) o López Castro (2000). Es en este contexto científico y bajo estos paradigmas donde, en cierta manera, se reproduce, con matices, el modelo colonial que estaba imperando, pero aplicado al caso mallorquín. En ello, no es baladí el empeño que puso Guerrero en parte, como muy bien comenta Ramon (2017: 79), por la cierta euforia que conllevó el descubrimiento de la factoría ebusitana de Na Guardis, pero también por la inicial resistencia a su aceptación dentro del contexto científico mallorquín (Guerrero, comunicación personal).

Por su parte, los matices del modelo colonial, que se desarrollan a finales de los años noventa y primera década del siglo xxI, tampoco son ajenos a la decisión misma, por parte de Guerrero y del equipo de la UIB, de excavar un yacimiento indígena como el Puig 
de sa Morisca, uno de los yacimientos centrales a la hora de entender el contacto entre las comunidades ebusitanas y el papel que desempeñan las comunidades postalayóticas. Finalmente, el proceso de deconstrucción del discurso en el que se sitúa actualmente la arqueología protohistórica balear no es comprensible sin tener en cuenta el auge en el estudio de las comunidades postalayóticas de estos últimos años, así como la fuerte incidencia que ha tenido en la comunidad científica la incorporación de los postulados derivados de las corrientes postcoloniales.

\section{Agradecimientos}

El presente artículo es parte de la transferencia de conocimientos del proyecto de investigación «Archipiélagos: paisajes, comunidades prehistóricas insulares y estrategias de conectividad en el Mediterráneo occidental. El caso de las Islas Baleares durante la Prehistoria» (HAR2015-67211-P), financiado por el Ministerio de Economía y Competitividad.

\section{Bibliografía}

ALBERO, D., 2017, The Times They Were a-Changing: Cultural Encounters, Social Transformations and Technological Change in Iron Age Hand-made Pottery from Mallorca (Spain), Journal of Mediterranean Archaeology 30-1, 105-131.

ALVAR, J., 1999, Los fenicios en Occidente, en J.M. BLÁZQUEZ, J. ALVAR y C.G. WAGNER (eds.), Fenicios y cartagineses en el Mediterráneo, Cátedra, Madrid, 313-447.

AMIN, S., 1975, El desarrollo desigual, Fontanella, Barcelona.

AMIN, S., 1976, Imperialismo y desarrollo desigual, Fontanella, Barcelona

ARRIBAS, A., TRÍAS, M. G., CERDÁ, D. y HOZ, J. De, 1987, El barco de El Sec (Costa de Calvià, Mallorca), Estudio de los Materiales, Palma.

AUBET, M. E., 1987, Tiro y las colonias fenicias de Occidente, Crítica, Barcelona.

BHABHA, H., 1994, The Location of Culture, Routledge, Londres.
BLANES I BLANES, C., BONET, J., FONT, A., ROSSELLÓ, A. M., 1990, Les Illes a les fonts clàssiques, Miquel Font, Palma.

BLÁZQUEZ, J. M., 1999, Los fenicios en Oriente, en J. M. BLÁZQUEZ, J. ALVAR y C. G. WAGNER (eds.), Fenicios y cartagineses en el Mediterráneo, Cátedra, Madrid, 313-447.

BOX, G. E., 1979, Robustness in the Strategy of Scientific Model Building, en R.L. LAUNER y G. N. WILKINSON (eds.) Robustness in statistics, Academic Press, Nueva York, 201-236.

CALVO M. y GUERRERO V., 2011, La cultura Postalayótica, en CALVO M. y AGUARELES A., (ed.), Calvià Patrimonio Cultural, Ajuntament de Calvià, Calvià, 113-146.

CALVO, M. y GARCÍA ROSSELLÓ, J., 2018 (e.p.), La presencia colonial en Mallorca: narrativas y propuestas, Treballs del Museu Arqueològic d'Eivissa $i$ Formentera 76.

CALVO, M., GARCIA ROSELLÓ, J., ALBERO y D., JAVALOYAS, D., 2014, Prácticas hibridas y espacios intermedios: los contextos cerámicos 
de la bahía de Santa Ponça (Calvià, Mallorca) (s. II a.C.), en C. FERRANDO y B. COSTA, (ed.), Im Amicitia. Miscel-lània d'estudis en homenatge a Jordi H. Fernández, Treballs del Museu Arqueològic d'Eivissa i Formentera 72, 113-132.

CALVO, M., QUINTANA, C. y GUERRERO, V., 2009, Territori i intercanvi: la influencia púnica en la comunitat talaiòtica del Puig de sa Morisca (Calvià), I Trobada d'arqueòlegs de les Illes Balears (Manacor 2006), Palma, 63-72.

CAMPS, J. y VALLESPIR, A., 1974, La estación del Turó de ses Belles (Calvià), en Prehistoria y Arqueología de las Islas Baleares, VI Simposio de Prehistoria Peninsular, 101-114.

CAMPS, J. y VALLESPIR A., 1998, El Turó de les Abelles, Consell Insular de Mallorca, Palma.

CHAMPION, T. C., 1989, Centre and periphery. Comparative studies in Archeology, Unwin Hyman, Londres.

CHILDE, V. G., 1988, Los orígenes de la civilización, Fondo de Cultura Económica, Madrid (original, 1925).

COLL CONESA, J., 1989, La evolución del ritual funerario en la Cultura Talayótica, Universitat Illes Balears (tesis doctoral inédita).

DELGADO, A., 2008, Colonialismos fenicios en el sur de Iberia: historias precedentes y modos de contacto, en G. CANO y A. DELGADO (eds.), De Tartessos a Manila. Siete estudios coloniales y postcoloniales, Universitat de València, Valencia, 19-49.

DEL OLMO G. y AUBET M. E, 1986, Los Fenicios en la Península Ibérica, Editorial Ausa, Sabadell.

DÍAZ-ANDREU, M., 2002, Historia de la arqueología en España, Estudios Clásicos, Madrid.

DIETLER, M., 1997, The Iron Age in Mediterranean France: colonial encounters, entanglements, and transformation, Journal of World Prehistory 11, 269-358.

DIETLER, M., 2009, Colonial encounters in Iberia and the Western Mediterranean: An exploratory framework, en M. DIETLER y C. LÓPEZ-RUIZ (eds.), Colonial encounters in Ancient
Iberia. Phoenician, Greek and Indigenous relations, University of Chicago Press, Chicago, 3-48.

DIETLER. N., 1995, The cup of Gyptis: rethinking the colonial encounter in early Iron-Age Western Europe and the relevance of world-systems models, Journal of European Archaeology 3-2, 89-111.

DOMÍNGUEZ MONEDERO, A., 2004, Els baleàrics segons les fonts literàries grecoromanes, en V. M. GUERRERO (coord.), Historia de les Illes Balears (vol. I), De la prehistòria i l'Antiguitat al mòn islàmic, Edicions 62, Barcelona, 247-280.

ENSEÑAT, C., 1981, Las cuevas sepulcrales mallorquinas de la Edad del Hierro, Excavaciones Arqueológicas en España, 118, Madrid.

FERNÁNDEZ-MIRANDA, M., 1978, Secuencia cultural de la prehistoria de las Baleares, Madrid, Consejo Superior de Investigaciones Científicas, Biblioteca Praehistorica Hispana XV.

FRANKENSTEIN, S., 1997, Arqueología del colonialismo. El impacto fenicio y griego en el sur de la Península Ibérica y el Suroeste de Alemania, Crítica, Barcelona.

GARCIA ROSSELLÓ, J. y CALVO M., 2018 (e.p.), Prácticas híbridas y prácticas técnicas en el sureste de Mallorca (siglo II a.C.), una aproximación desde la arquitectura, Treballs del Museu Arqueològic d'Eivissa $i$ Formentera 76.

GARCÍA ROSSELLÓ, J., 2010, Análisis traceológico de la cerámica. Modelado y espacio social durante el Postalayótico (s. V-I AC) en la península de Santa Ponça (Calvià, Mallorca), Universitat de les Illes Balears, Palma (tesis doctoral inédita).

GARNSEY, P. D. y WHITTAKER, C., 1978, Imperialism in the Ancient World, Cambridge University Press, Cambridge.

GELABERT BATLLORI, L., 2014, La dinàmica de consum de vi al poblat de Son Fornés: inicis i finals d'una nova mercaderia, Bolletí de la Societat Arqueològica Lul-liana 70, 15-34.

GELABERT BATLLORI, L., 2013, Circulació $i$ consum de mercaderies a la Prehistòria Balear. El cas de Son Fornés (Mallorca) a partir de la materialitat 
amfòrica, Universidad Autónoma de Barcelona, Barcelona (tesis doctoral inédita).

GORNES, S., GUAL, J. y LÓPEZ, A., 1992, La colonització púnica a les Balears. Una revisió crítica, en X Jornades d'Estudis Històrics Locals, La prehistòria de les Illes de la Mediterrània Occidental, Palma, 443-452.

GUERRERO AYUSO, V., 1981, Los asentamientos humanos sobre los islotes costeros de Mallorca, Trabajos del Museo de Mallorca, 31, Dirección General de Bellas Artes Archivos y Bibliotecas, Madrid.

GUERRERO AYUSO, V., 1982, Los núcleos arqueológicos de Calvià, Ayuntamiento de Calvià, Calvià.

GUERRERO AYUSO, V., 1984a, El asentamiento púnico de Na Guardis, Excavaciones Arqueológicas en España, 133, Madrid.

GUERRERO AYUSO, V., 1984b, La colonización púnico ebusitana de Mallorca. Estado de la cuestión, Trabajos del Museo Arqueológico de Ibiza 11, Museo Arqueológico de Ibiza, Ibiza.

GUERRERO AYUSO, V., 1985, Indigenisme i colonització púnica a Mallorca, Ajuntament de Ses Salines, Mallorca.

GUERRERO AYUSO, V., 1986, El impacto de la colonización púnica en la Cultura Talayótica de Mallorca, en Los Fenicios en la Península Ibérica, vol II 339-375, Ausa, Sabadell.

GUERRERO AYUSO, V., 1987, La Colonia de Sant Jordi (Mallorca). Estudis d'Arqueologia i epigrafía, Centre d'Estudis Gabriel Alomar, Palma.

GUERRERO AYUSO, V., 1989, Puntos de escala y embarcaderos púnicos en Mallorca: Illot d'en Sales, Bolletí de la Societat Arqueològica Lul-liana 45, 27-38.

GUERRERO AYUSO, V., 1991, Naturaleza y función de los asentamientos púnicos en Mallorca, Atti del II Congreso Internazionale di Studi Fenici e Punici, vol. III, Roma, 923-930.

GUERRERO AYUSO, V., 1992, Precisiones en torno a la colonización púnica de Mallorca, en $X$ Jornades d'Estudis Històrics Locals. La prehistòria de les Illes de la Mediterrània Occidental, Palma. 479-490.
GUERRERO AYUSO, V., 1993, La colonización prerromana de las Baleares, Hispania Antiqva XVII, 461-468

GUERRERO AYUSO, V., 1994, Formación social indígena y relaciones coloniales en la protohistoria balear, Gerión 12, 155-196

GUERRERO AYUSO, V., 1997, La colonización púnica de Mallorca. La documentación arqueológica y el contexto histórico, El Tall, Palma.

GUERRERO AYUSO, V., 2004a, Colonos e indígenas en las Baleares prerromanas, Colonialismo e interacción cultural: el impacto fenicio púnico en las sociedades autóctonas de occidente. XVIII Jornadas de arqueología fenicio-púnica, Treballs del Museu Arqueologic d'Eivissa i Formentera 54, 145-203

GUERRERO AYUSO, V. M., 2004b, Las islas Baleares en las rutas de navegación del Mediterráneo central y occidental, en V. PEÑA A. MEDEROS y C. G. WAGNER, (eds.), La Navegación Fenicia: Tecnología Naval y Derroteros, Centro de Estudios Fenicios y Púnicos, Univ. Complutense, Madrid, 85-134.

GUERRERO AYUSO, V. y QUINTANA, C., 2006, Comercio y difusión de las ánforas ibéricas en Baleares, Quaderns de Prehistoria i Arqueologia de Castelló 21, 153-182

GUERRERO AYUSO, V., CALVO TRÍAS, M. y SALVÁ SIMONET, B., 2002, La cultura Talayótica: una sociedad de la edad del hierro en la periferia de la colonización fenicia, Complutum 13, 221-225.

GUERRERO AYUSO, V., CALVO TRIAS, M. y GORNÉS HACHERO, S. J., 2006, Mallorca y Menorca en la Edad del Hierro, Historia de las Baleares, vol. II, Rey Sol, Palma.

GUERRERO AYUSO, V., CALVO, M. y SALVÀ, B., 2007, Insularity and the indigenous world on the periphery of the system: The Balearic islands (Majorca and Minorca) between the $6^{\text {th }}$ and $1^{\text {st }}$ B.C., en P. VAN DOMMELEN y N. TERRANATO (eds.), Articulating local cultures: power and identity under the expanding Roman Republic, Journal of Roman Archaeology. Suplementary series, 63. 
HERNÁNDEZ, J., 1998, Son Real. Necrópolis talayótica de la edad del Hierro. Estudio arqueológico y análisis social, Arqueomediterránea 3, Barcelona.

HERNÁNDEZ, J. y SANMARTÍ, J., 1999, El santuari de sa Punta des Patró a l'àrea cultual i funeraria de Son Real (Santa Margalida, Mallorca). Avanç dels resultats, Mayurqa 25, 113-138.

HERNÁNDEZ, J., SANMMARTÍ, J., MALGOSA, A. y ALESAN, A., 1998, La necròpolis talaiòtica de s'Illot des Porros, Pyrenae 29, 69-95.

HERNÁNDEZ-GASCH, J. y QUINTANA, C., 2013, Cuando el vino impregnó la isla de Mallorca: el comercio púnico-ebusitano y las comunidades locales durante la segunda mitad del siglo v y el siglo IV a.C., Trabajos de Prehistoria 70-2, 315-331.

HERNANDO, A., 2002, Arqueología de la identidad, Madrid, Akal.

JAVALOYAS MOLINA, D., 2010, Hacia una historia praxiológica de la arqueología prehistórica española. La arqueología mallorquina como caso de estudio, Complutum 21-1, 27-44.

JAVALOYAS MOLINA, D., (en preparación), Arqueología y prehistoria durante la dictadura franquista (1939-1975) en Mallorca y España, Universidad de las Islas Baleares (tesis doctoral).

JENSEN, O. W., 1997, When archaeology meets Clio. A critical reflection on writing the history of archaeology, Archaeological review from Cambridge 14, 79-92.

LÓPEZ CASTRO, J. L., 2000, Formas de intercambio de los fenicios occidentales en época arcaica, en P. FERNÁNDEZ, C.G. WAGNER y F. LÓPEZ (eds.), Intercambio y comercio preclásico en el Mediterráneo. Actas I coloquio del Centro de Estudios Fenicios y Púnicos, Madrid, 123-136.

MAÑA, J., 1950, Sobre tipología de ánforas púnicas, en VI Congreso Arqueológico del Sudeste Español, Alcoy, 204-206.

MARTÍN, R., ARGÜELLO, J. y JOVANI, S., 2015, El yacimiento púnicoebusitano de Sa Galera (Can Pastilla - Palma), en A. MARTíNEZ y G.
GRAZIANI (coords.), VI Jornades d'Arqueologia de les Illes Balears, Sant Francesc Xavier, 141-152.

MAYORAL, F., 1983, Aproximación a la fase postalayótica mallorquina: la cerámica, Universidad Autónoma de Barcelona (tesis de licenciatura inédita).

MORO, O., 2007, Arqueología prehistórica e historia de la ciencia. Hacia una historia crítica de la arqueología, Bellaterra, Barcelona.

MOSCATI, S. (1983) Cartagineses, Encuentro, Madrid. PERELLÓ, L., 2017, Tecnología metalúrgica del cobre y bronce durante el período Postalayótico en Mallorca (ca. s. vi aC-s. I aC), Universitat de les Illes Balears, Palma (tesis doctoral inédita).

PERICOT, L., 1972, The Balearic Islands, Thames \& Hudson, Londres.

POLANYI, K., 1975, Traders and Trade, en J. A. SABLOFF y C. C. LAMBERG-KARLOVSKY (eds.), Ancient Civilization and Trade, University of New Mexico Press, 133-154.

QUINTANA, C., 2018 (e.p.), Mallorca durante la segunda edad del hierro. Interacción entre ebusitanos y comunidades autóctonas a partir del material anfórico (segunda mitad del siglo v - siglo III ane), Treballs del Museu Arqueològic d'Eivissa i Formentera 76.

QUINTANA, C., 2006, Comerç en el món talaiòtic: el conjunt amfòric del poblat de Ses Païsses (Artà, Mallorca), Pyrenae 37-2, 47-69.

QUINTANA, C., 2015, El Túmul de son Ferrer (Calvià, Mallorca), centro receptor secundario. Estudio de las ánforas, Materialidades, Perspectivas en cultura material 3, 1-33.

QUINTANA, C. y GUERRERO, V., 2004, Las ánforas del Puig de sa Morisca. Los contextos del siglo IV a.C., en J. SANMARTÍ, D. UGOLINI, J. RAMON y D. ASENSIO (eds.), La circulació d'àmfores al Mediterrani occidental durant la Protohistòria (segles VIII-III aC, aspectes quantitatius i anàlisi de continguts. Arqueomediterrània 8, Barcelona, 253-260.

RAMON, J., 2017, Pecios y ¿colonias? Materiales púnicos en las Islas Baleares, en F. PRADOS, 
H. JIMÉNEZ y J. J. MARTÍNEZ (coord.), Menorca entre fenicis i púnics, Cercle Artístic de Ciutadella, Publicacions des Born, 25, 41-84.

RAMON, J., 1981, La producción anfórica púnicoebusitana, Ministerio de Cultura, Ibiza.

RAMON, J., 1991, Las ánforas púnicas de Ibiza, Trabajos del Museo Arqueológico de Ibiza 23, Museo Arqueológico de Ibiza. Ibiza.

RAMON, J., 1995, Las ánforas fenicio-púnicas del Mediterráneo central y occidental, Col-lecció Instrumenta 2, Universitat de Barcelona, Barcelona.

ROSSELLÓ-BORDOY, G., 1973, La cultura talayótica en Mallorca, Cort, Palma.

ROWLANDS, M., LARSEN, M. y KRISTIANSEN K., 1987, Centre and periphery in the ancient world. News directions, Cambridge University Press, Cambridge.

SAID, E., 1993, Culture and Imperialism, Knopf, Nueva York.

SØRENSEN, M., 1984, Changing images of Archaeology. South Scandinavian archaeology: 1818 to 1978, Archaeological review from Cambridge 3-1, 38-47.

STEIN, G. J., 2005, Introduction. The comparative archaeology of' colonial encounters, en G.J. Stein (ed.), The archaeology of' colonial encounters, School of American Research Press, Santa Fe, 1-29.
VAN DOMMELEN, P., 1998, On Colonial grounds. A comparative study of colonialism and rural settlement in first millennium BC west central Sardinia, Leiden.

VAN DOMMELEN, P., 2000, Momenti coloniali. Cultura materiale e categorie coloniali nell'archeologia classica, en N. TERRENATO (ed.), Archeologia Teorica, Florencia, 293-310.

VAN DOMMELEN, P., 2006, Colonial Matters. Material Culture and Postcolonial Theory in Colonial Situations, en C. TILLEY, W. KEANE, S. KUECHLER, M. ROWLANDS y P. SPYER (eds.), Handbook of Material Culture, Sage, Londres, 104-124.

VIVES, J., 2005, Negociando encuentros: Situaciones coloniales e intercambios en la costa oriental de la península Ibérica (ss. VIII-VI a.C.), Cuadernos de Arqueología Mediterránea, 12, Bellaterra.

WAGNER, C. G. y ALVAR, J., 1989, Fenicios en Occidente, La colonización agrícola, Rivista di Studi Fenici XVII 1, 61-102.

WAGNER, C. G., 1993, Aspectos socioeconómicos de la expansión fenicia en Occidente: El intercambio desigual y la colonización agrícola, Revista d'Estudis d'Història Econòmica 1, 1-37.

WALDREN, W. H., 1982, Balearic prehistoric ecology and culture, British Archaeological Reports International Series 149, Oxford. 
